\title{
ON TAKING OFF THE WASTE GAS FROM OPEN-TOPPED BLAST FURNACES.
}

By Mr. SAMUEL LLOYD, JuN, OF WeDNESBURY.

The writer having been requested at the last meeting of the Institution to give a description of the plan now adopted at the Old Park Iron Works, Wednesbury, and several other works, for drawing off the combustible Waste Gas from Blast Furnaces without the use of a close top, has collected the following information on the subject. The plan now so successfully in operation was not hit upon at once, but only tried as a kind of last resource, after other modes of taking off the gas had been abandoned on account of being so injurious to the working of the furnace as to be inadmissible.

At the Old Park Iron Works the first attempt to make use of the gas was in 1849. It was thought that if three openings, each about 2 feet square, were made into the furnace about 12 feet below the filling holes, at equal distances round the circumference, and were connected by a brick flue to the boilers, enough gas would issue through them to raise the greater part of the steam required for the blast engine. These holes were accordingly made, opening into the brick flue which was built round the outside of the furnace. Practically however this arrangement did not answer, for it was found impossible to keep the brick flue air-tight; and it had not been long at work before several explosions took place; at last it blew up with a force which seemed almost to shake the whole works, and sent the bricks flying in all directions. To remedy this a wrought iron tube was substituted for the brick flue. This was a great improvement, but still sufficient gas would not come down the tabe to be of much service, owing to the blast engine chimney not being powerful enough, as it was only about 90 feet high and about 2 feet 4 inches square inside at the top, for seven boilers, several of which had still to be 
fired with slack to supply the blast engine with the required quantity of steam; so that there was but little draught left for the one or two boilers to which the gas was applied.

It was soon found that the holes in the furnace had a tendency to clinker up whenever the furnace was standing, owing to a return current of air setting in through them into the furnace, which occasioned a considerable quantity of mine to set quite hard around and beneath the holes, causing the furnace to slip and work so badly that they had to be filled up again. Instead of these a wrought iron cylinder was introduced into the furnace top, and the end of the prought iron gas tube leading to the boilers was inserted into the side of the furnace. Only a small portion of the gas however found its way down to the boilers, so that nearly as much flame appeared at the tunnel head as before the insertion of the cylinder.

At the same time an attempt was made to use the gas in one of the hot-air ovens, without making any alteration in the oven itself or its three chimneys, which were only about 6 feet high. A fan was fixed in a cast iron box, from which cast iron pipes 12 inches diameter were carried up outside the furnace, the end pipe entering into the furnace behind the cylinder. A larger pipe was fixed to convey the gas from the fan to the oven. The fan was driven at 900 to 1000 revolutions per minute, which forced a considerable quantity of gas into the oven, the fan shaft being kept cool by being made hollow, with a small stream of water trickling through it. This experiment was not continued any great length of time, in consequence of the fan which was an old one breaking down; but it proved that with a fan of sufficient size it would be quite possible to draw off all the gas given off by a furnace. The writer however recommends as preferable for such a purpose an exhauster on the plan of Lemielle's described in the paper read before the Institution in 1858. This machine is extensively used in Belgium and France for ventilating coal mines, and from its slow motion appears preferable to a fan, which from its quick speed is so likely to get out of order.

The furnace had not been working long with the wrought iron cylinder inserted in the top before the cylinder was burnt off and fell in, owing to the great heat at the furnace top in consequence. of so 
little of the gas being drawn down to the boilers. It was evident from these experiments that a much more powerful chimney was needed to draw down the gas efficiently. A stack was accordingly erected which is 130 feet high and 6 feet 6 inches diameter inside at the top; and a new cylinder like the previous one was then inserted in the furnace top. This resulted in plenty of gas being drawn down, working very well under the boilers. The furnace however was injuriously affected, the make of iron being lessened and the quality not so good as before, the iron being white with a burden of fuel which ought to have produced grey forge iron. Several alterations were made successively in the plan of taking off the gas, but the furnace was more or less injuriously affected by each, the make of iron being in every case diminished and the quality variable. On several occasions portions of the coke and ironstone that had been put in at the top of the furnace were shovelled out at the bottom very much in the same state as when they were put in. A shorter cylinder and one or two others of different sizes were also tried, but without satisfactory result. The use of the gas was therefore entirely abandoned at the above works.

In $1852 \mathrm{Mr}$. Blackwell endearoured to make an economical use of the waste gas at the Bilston New Furnaces, and communicated the results of this attempt to the Institution in a paper read in October of that year. In the first instance the furnace upon which he tried the experiments was blown in with a cylinder inserted at the top; and it was found as at the Old Park Iron Works that constant slipping and fretting tujeres with all their attendant bad results were the consequence. A close top was therefore tried, closed with a cone that was lowered for charging, and a great improvement in the working of the furnace immediately resulted; yet nothing but white iron was produced. In order if possible to produce grey iron, the burden was lightened two or three times; but although the cinder became exceedingly grey, still the iron was white. It was evident that the white iron was caused by the close top; and as it was important to produce grey iron, it was determined to sacrifice the use of the gas entirely, rather than continue making white iron. The gas was 
therefore allowed to escape freely by large openings made in the gas main; when a decided change was at once manifest; the iron became grey and the furnace worked with regularity. The white iron had evidently been caused by the pressure produced by the close top; and the furnace appeared to be so sensitive to the slightest pressure that the writer was informed on visiting the works at the time that even a strong wind blowing into the opening through which the gas was principally escaping was found to throw the furnace back to white iron.

At the Brymbo Iron Works, near Wrexham, the first attempt to use the gas was made in 1849 by the insertion of a cylinder in the furnace top similar to the one already described as tried about the same time at Wednesbury. Though not so injurions to the working of the furnace as when applied at Wednesbury and Bilston, its effect was sufficiently unsatisfactory to cause the loss at the furnace considerably to exceed the saving at the boilers; so that after some months' trial it was taken out of the furnace, and the use of the gas abandoned for some time. A year or two afterwards, about the same time that Mr. Blackwell made the experiment just mentioned, a close top was tried on one of the Coalbrookdale furnaces at Horsehay, made with a cone similar to those that were answering satisfactorily at the Ebbw Vale furnaces in South Wales: but the working of the furnace was so deranged by the close top that it had to be taken out; and no attempt has since been made to economise the waste gas in Shropshire. Soon after this close top was taken out it was removed to Brymbo, where it was tried; but the furnace worked worse than when the cylinder was used. It was therefore taken out again, and no further attempt was made to use the gas there till 1857, when Mr. Charles E. Darby decided to try the plan which forms the subject of the present paper.

This plan consists simply in inserting into the open furnace top a continuation of the descending tube conveying the gas down to the boilers, which reaches down into the centre of the materials to a sufficient depth to secure drawing off the gas without admixture of air.

Fig. 1, Plate 55, shows the general arrangement of the apparatns for taking off the gas from the open-topped furnace at Brymbo, and burning it under the steam boilers of the blowing engine. The 
wrought iron tube A for taking off the gas is 3 feet 9 inches diameter outside, and is inserted into the centre of the open top of the furnace which is 9 feet diameter. The descending main $\mathbf{B}, 3$ feet diameter, conveys the gas down the outside of the furnace to the horizontal main $C$, which passes across the ends of the three steam boilers, one of which is shown in section at $D$. The gas is delivered by a branch pipe $E, 22$ inches diameter, into the furnace of each boiler just above the firedoor, where it is burnt by admitting the necessary supply of air through holes in the firedoors and through sliding doors above them when more air is required. The supply of gas is regulated or shut off by a throttle valve in the branch pipe $E$. The ashpits of the three boilers under which the gas is burnt are closed by iron doors. A small fire is kept on the grates, close to the mouth of the pipe $\mathbf{E}$ through which the gas is admitted, as a precaution against its ever entering under the boilers in an unignited state after any temporary stoppage, and then causing an explosion by becoming suddenly ignited. The gas is drawn down from the furnace by the draught of the chimney $F$, which is about 90 feet high and rises about 40 feet above the level of the furnace top; it is 2 feet square at the top, giving an area of 4 square feet. The draught of this chimney, which is equal at its base to 0.74 to 0.84 inch column of water when the gas is being used, is found to be quite sufficient for drawing off enough gas for two boilers, but scarcely powerful enough to draw down the quantity required for three; for when the three are on, one third more steam is not raised, as would be the case if the chimney were sufficiently powerful, since the furnace makes gas enough for three boilers, a quantity always escaping at the tunnel head even when the three are on. The draught for the fourth boiler, which is worked with a coal fire alone, is supplied from another chimney.

Fig. 6, Plate 58, shows an enlarged vertical section of the end of the gas tube that is inserted into the open top of the furnace. It consists of a wrought iron bend $A$, made of $\frac{1}{2}$ inch boiler plate, 3 feet in diameter, with a thick cast iron cylinder $G$ attached to it, which is buried in the charge of the furnace, and secured to the wrought iron bend by a rivetted joint. The cast iron cylinder is 3 feet 6 inches long below the joint, and recessed at top to form a flush joint outside; 
the metal is $1 \frac{3}{8}$ inch thick, and increased to 2 inches thick at the bottom edge. The bend and cylinder are supported in their position by a centre bolt from a cross girder resting on the tunnel head; and the bend is bolted by an angle iron flange to the end of the gas main, which passes out in the space between two of the ordinary filling holes, four in number, which are thus not interfered with. The bottom of the gas tube is 5 feet below the level of the filling plates; and the materials in the furnace are filled up to the top of the cast iron cylinder $G$, and should be kept at that level so as to ensure the end of the tube being always sufficiently covered in the furnace to prevent air being drawn in with the gas. A wrought iron hinged door $\mathbf{H}$, Fig. 1, of about 3 square feet area, with a 56 lbs. weight upon it to keep it closed, is provided upon the upper part of the gas main, opening outwards, to act as a safety valve in case of any accidental explosion.

The first tube inserted into the furnace in 1857 was made as an experimental one of old wrought iron plates, and lasted only about two months. It was replaced by a stronger one made of $\frac{1}{2}$ inch plates; but as this lasted only about five months and the next one made of the same strength lasted only about the same time, it was decided to make the part which descends into the materials of the furnace of cast iron, because when made of wrought iron it had a tendency to collapse under the pressure of the surrounding materials whenever it became hotter than usual. Two of these cast iron ends have now been used, as shown in Fig. 6, Plate 58, lasting about eleven months each, and satisfactorily resisting the heat and compression to which they are subjected, without requiring any repair or attention during that time. When the cylinder requires to be replaced in consequence of the bottom burning away, the whole bend is detached and lifted out, and a fresh one fixed in its place; and so little work is required to make this change that the whole delay cansed to the furnace was only about 3 hours the last time the cylinder was renewed. The plates of the descending gas main B, Fig. 1, Plate 55, are only $\frac{1}{8}$ inch thick, and though the apparatus has been erected ten years are still in good order; a greater thickness however is desirable, to provide against waste from oxidation. 
In consequence of the success attending the new arrangement for using the gas at Brymbo, the writer recommended its adoption at the Old Park Iron Works, and it was decided to alter accordingly the apparatus previously tried there.

Fig. 2, Plate 56, shows the apparatus as now at work at the Old Park Iron Works. The wrought iron gas tube A is 4 feet 6 inches diameter inside at the bottom and 4 feet 9 inches at the upper part, and is made of $\frac{1}{2}$ inch boiler plate; it has a cast iron cylinder $G, 4$ feet 6 inches diameter, rivetted to the bottom, 2 inches thick at the lower edge and 3 feet 6 inches in length, as shown enlarged in Fig. 7, Plate 58, extending 6 feet below the level of the filling plates. The tube $\mathrm{A}$ is carried by two cast iron girders I I fixed across the tunnel head; and the branch tube $K$ is carried out of it at a height sufficient to allow of the workmen passing underneath, so that the ordinary filling holes of the furnace are not interfered with. The branch tube $K$ is carried by a cast iron saddle upon the girder $I$, as shown in Fig. 3, Plate 56, which serves to protect the underside of the tube from being injured by the flame of the furnace. The descending gas main $B$ is flat bottomed, 4 feet 3 inches wide by 4 feet 6 inches high, and inclines gradually downwards to the steam boilers of the blast engine, which are at a distance of about 200 feet from the furnaces. Two safety valves $\mathrm{HH}$ are provided on the gas main as a provision against any explosion.

One of the boilers is shown in section at $D$, and the gas is supplied to each by a rectangular tube $E$, of 4 square feet area, brought down from the horizontal main $\mathrm{C}$ which extends along the end of the boilers; the supply of gas to each boiler being regulated by a flat slide valve, as shown in the drawing, at the top of the tube $\mathbf{E}$. The gas is admitted to the furnace over the firedoor and thrown against an inclined brick arch, which deflects it downwards to mix with the air entering at the firedoor. The boiler has two flues and is fired underneath, the flame passing underneath to the back, returning through the flues and back on each side to the chimney $\mathbf{F}$, which is 130 feet high and extends 85 feet above the level of the materials in the furnace. The ashpit is bricked up, but a small fire is kept under each of the boilers close to the firedoor, as a precaution against the 
gas ever passing under the boiler unignited. There are six boilers heated by the gas from the one furnace; these with two others supply the steam for the engine blowing three furnaces, a refinery, two cupolas, and about thirty smiths' fires.

In the first application of the gas apparatus to this furnace, it was thought desirable to protect the cast iron cylinder $G$ in the furnace top by a casing of firebrick, and it was therefore constructed as shown in Fig. 8, Plate 58, having six flanges cast upon it, extending round the cylinder and supporting rings of frebrick, the bricks being secured by bolts passed down through holes drilled in each vertical row of the bricks. This construction was successful as regarded the firebrick casing, but it failed from a defect in the mode of making the joint to the wrought iron tube above, which was made by projecting jointed catches $L$ on the top of the cast iron cylinder, resting; upon lugs fixed inside the bottom edge of the wrought iron tube. These became overheated and gave way, in consequence of the furnace when standing during Sunday having been left charged full to the top, so that the cast iron cylinder was exposed to great heat at the joint without the cooling effect of the gas being drawn off: the cast iron cylinder was cracked, and in a day or two afterwards the wrought iron catches $L$ became so softened by the heat as to give way and let the cylinder drop into the furnace. A plain cast iron cylinder rivetted upon the bottom of the gas tube was consequently substituted, as shown in Fig. 7, Plate 58, similar to the one used at Brymbo; this has now been in use about four months, and the riretted joint has proved quite satisfactory. It is contemplated to apply the gas from another furnace to heat the hot-blast stoves, in which case it is proposed to use a cylinder cased with firebrick, as shown in Fig. 8 , but fixed simply by a rivetted joint at the top, as shown in Fig. 7 ; and there seems good reason to expect that the cylinder will then prove very durable, and last as long as the furnace hearth.

The main injury was found to be received by the cylinder when the furnace was standing. If it stood rather longer than usual at tapping time, the heat of the materials round the tube increased to such an extent on one or two occasions as to make the tube almost white hot. To prevent the present tube being injured in this way, 
whenever the furnace has to stand any length of time for tuyering or any other purpose, the materials in the furnace are allowed to work down. As they work down towards the bottom of the cylinder, the quantity of gas passing to the boilers diminishes, so that the engineman shuts it off from one boiler after another, until by the time the bottom of the cylinder is about to become uncovered it is shut off from the last boiler. If this should be omitted to be done soon enough, no explosion is found to result, but a back current from the boilers to the furnace is apt to set in and fire the soot and tar in the tubes; but these soon become extinguished when the valves are all shut. As soon as the blast is put on the furnace again, it is filled with one or two charges of materials which are kept at the furnace top ready; the valves at the boilers are then again opened, and a plentiful supply of gas is the immediate result. It was feared that in taking off the gas there might be a difficulty in the furnace standing for 12 hours every Sunday, as is the practice at the Old Park Iron Works; but by leaving it on the Sunday morning with the level of the materials below the bottom of the gas tube, no difficulty whatever has been experienced in letting the furnace stand as usual. Since the gas has been used, the last six barrows of coal and coke have been omitted in the last two charges every Sunday morning, for the purpose of lessening the amount of heat directly under the gas tube, without any injurious effect on the furnace.

The same plan of taking off the gas has also been employed for the last three months by Messrs. Fletcher Solly and Urwick at the Willenhall Furnaces, Willenhall, as shown in Fig. 4, Plate 57. In this case the gas is taken from one furnace out of three, and is burnt under the boilers of the blast engine, serving to raise all the steam for blowing the three furnaces. This application has proved so satisfactory that the apparatus is now being applied to one of the other furnaces, for the purpose of heating the hot-air stoves by the gas. In the boiler furnaces a little coal was at first kept burning, as a precaution to ensure the gas being always ignited; but it has not been considered necessary to continue this, and the firegrates have been covered with a layer of firebricks, as shown at M, Fig. 4, to form a 
complete hot chamber for the combustion of the gas : this arrangement has now been in constant use for nearly two months without any objection being experienced. The chimney for the blast engine boilers is 120 feet high, and 8 feet diameter inside all the way up.

The cast iron gas cylinder G, Fig. 4, Plate 57, is in this case made bell-mouthed, as shown enlarged in Fig. 5 ; it is attached to the wrought iron tube $A$ by four large wrought iron hooks $L$ rivetted on the tube and catehing lugs cast on the top edge of the cylinder; there are also four intermediate screw bolts and lugs $\mathrm{N}$ to hold up the cylinder in case of any of the hooks giving way. This cylinder was originally cased with firebricks, as shown in Fig. 5, but some of the firebricks have come off, in consequence of their being separately held by bolts screwed in the cast iron.

The furnace at the Old Park Iron Works was previously 8 feet diameter at the filling holes; but as it was desired not to diminish the area of opening at the top by the insertion of the gas tube, the furnace top was taken down about 9 feet, and rebuilt vertically, as shown in Fig. 2, Plate 56, so as to obtain a diameter of 10 feet at the filling holes. By this means the area of opening around the gas tube was made greater than the previous area of the entire open top. The portion of the gas tube $A$ which descends into the material of the furnace is $4 \frac{1}{2}$ feet diameter, giving 16 square feet area, and the annular area around it is $78-16=62$ square feet area; while the previous diameter of 8 feet gave only 50 square feet area. The effect of this increased area of opening at the furnace top is to allow the most complete freedom for the gas to escape at all times ; for even if the gas valves be closed at all the boilers and no gas be used under them from any cause, there is still an area left one fifth greater than before for the gas to escape at the tunnel head.

The descending gas main B to the boilers, Fig. 2, Plate 56, is 16 square feet area. The chimney $F$ is 130 feet high and $6 \frac{1}{2}$ feet diameter inside at the top or 33 square feet area, and is sufficiently powerful to draw off ordinarily the whole of the gas from the furnace; as shown by the fact that the top of the furnace is frequently so free from flame that a person might safely walk across the top of the 
materials. At times however, owing to the materials giving out more gas than-is drawn down the tube and consumed under the boilers, a considerable quantity escapes in flame at the furnace top. This is an evident advantage of the plan of taking off the gas from an open-topped furnace; since the furnace is in no case liable to be injuriously affected by any back pressure, the open top around the gas tube acting always as a self-acting safety valve, which never allows the pressure inside the gas tube to exceed a definite small amount corresponding to the resistance of the 5 feet depth of materials through which any gas must pass that does not enter the tube. From experiments formerly made by Bunsen and Playfair it was found that the pressure that exists at 5 feet below the top of the materials in blast furnaces is equivalent to a column of water $\frac{1}{8}$ inch high. This is corroborated by the result of measuring the pressure in the top of the gas tube at the Old Park Iron Works, in which the above pressure was indicated at a time when there was a considerable quantity of gas escaping round the tube; at another time when scarcely any gas was escaping the pressure was found to be less than half that amount, being barely perceptible. It is a rather remarkable circumstance that every stroke of the blast engine was perceptible at the top of the furnace in the increased pressure of gas in the tube, as shown by an ignited jet of the gas issuing through a small hole in the tube, which increased and diminished with each stroke of the engine. From this it is evident that any restraint upon the free escape of the gas must have its effect apon the whole furnace, checking to a proportionate extent the entrance of the blast into the furnace, and consequently retarding its action and diminishing its make so long as such a back pressure exists.

The working of the open-topped furnace at the Old Park Iron Works from which the gas has been taken off has clearly proved that allowing the gas to escape at the furnace top with the greatest freedom possible is very beneficial to the working of the furnace; for since taking off the gas the average make per week has been greater than previously, while the materials used have been exactly the same. This will be seen by the following particulars, which are in the first place the amount of iron made by the furnace called No. 2 during the 
three months before the gas was taken off from it, and also the make of another furnace called No. 3, of the same size, working at the same time, the same materials and same quantity of blast being supplied to each furnace: and secondly the make of the same two furnaces during the last three months, while the gas has been taken off from No. 2 and not from No. 3.

\begin{tabular}{|c|c|c|}
\hline & $\begin{array}{l}\text { No. } 2 \text { Furnace. } \\
\text { Tons. }\end{array}$ & $\begin{array}{l}\text { No. } 3 \text { Furnace. } \\
\text { Tons. }\end{array}$ \\
\hline before taking off gas. & 1486 & 1519 \\
\hline $\left.\begin{array}{c}\text { otal make of iron during last } 3 \text { months } \\
\text { with gas taken off from No. } 2 \text { furnace }\end{array}\right\}$ & 1652 & 1545 \\
\hline
\end{tabular}

This increased make may be partly accounted for by the increased amount of blast supplied to the furnace by the blast engine since the gas has been taken off, owing to the pressure of the steam being kept up more uniformly since the boilers have been heated by gas. It is also probably due in part to the combustion of the fuel at the top of the furnace being less rapid, in consequence of there being less heat at that part, which causes it to give out more heat and produce a better effect when it descends into the lower part of the furnace. This also accounts for a perceptibly greyer quality of iron being made by every furnace from which the gas has been taken off, when the same burden has been continued that was on the furnace before taking off the gas: except at Brymbo, where a leaner ironstone has been used since the gas apparatus has been at work. The increased make may also be partly due to the mode of filling, with the gas tube in the centre of the furnace top, which causes the materials to be spread in more uniform layers round the outside of the furnace. It is possible it may also to some slight extent result from a large proportion of the dust, which is thrown into the furnace along with the calcined ironstone and coke, being driven out of the furnace again through the gas tube, thus enabling the furnace to drive faster, in consequence of the blast not being impeded in its passage through the furnace by the presence of this useless dust.

At the Brymbo Iron Works the furnace No. 2 from which the gas is taken off has been working alongside another furnace No. 1 of 
rather larger size, both being fed with the same materials. The following comparative statement shows the average weekly make of iron from each furnace for a whole year before the gas was taken off from No. 2 furnace, and for a corresponding period since :-

\begin{tabular}{|c|c|c|}
\hline & $\begin{array}{l}\text { No. } 2 \text { Furnace. } \\
\text { Tons. }\end{array}$ & $\begin{array}{l}\text { No. } 1 \text { Furnace. } \\
\text { Tons. }\end{array}$ \\
\hline 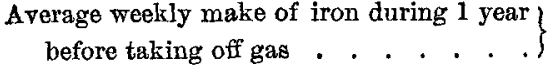 & $104 \frac{1}{4}$ & $105 \frac{8}{4}$ \\
\hline $\left.\begin{array}{c}\text { verage weekly make of iron during } 1 \text { year } \\
\text { with gas taken off from No. } 2 \text { furnace }\end{array}\right\}$ & $108 \frac{1}{2}$ & $110 \frac{3}{4}$ \\
\hline
\end{tabular}

The result shows a slight increase in the average make of both furnaces since the gas was taken off, of about the same amount in each, namely 4 per cent. in No. 2 and $4 \frac{3}{4}$ per cent. in No. 1 furnace.

The saving effected at Brymbo in cost of fuel for the blast engine boilers by taking off the gas is shown by the following statement of the consumption of slack, reckoned as good coal, during the two years before and after the gas apparatus was applied:-

Coal consumed at boilers

per ton of iron made $\}$ before taking off gas . . . 5.94 owts.

Ditto ditto after taking off gas . . . . $1.29 \mathrm{ewts.}$

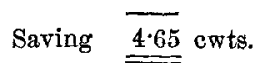

Say $4 \frac{1}{2} \mathrm{cwts}$. saving per ton of iron made, which at $3 d$. per cwt. makes 1 s. $1 \frac{1}{2} d$. saving per ton of iron made; and this on the total make of 11,285 tons of iron from the two furnaces during the year after taking off the gas amounts to a total saving of $£ 635$. This is exclusive of the saving of labour in firing, wheeling away ashes, and boiler repairs, the amount of which is considerably lessened.

The consumption of coal in the two furnaces at Brymbo per ton of iron made, during the same two years before and after using the gas from No. 2 furnace, was as follows :-

$\left.\begin{array}{c}\text { Coal consumed in furnaces } \\ \text { per ton of iron made }\end{array}\right\}$ before taking off gas . . . 44.18 cwts. Ditto ditto after taking off gas. . . . $43.92 \mathrm{cwts}$.

The total consumption of coal per ton of iron made, including the blast engine boilers and hot-air stoves, was as follows:-

$\left.\begin{array}{l}\text { Total Coal consumed } \\ \text { per ton of iron made }\end{array}\right\}$ before taking off gas . . . $52.09 \mathrm{cwts}$. Ditto ditto after taking off gas. . . 47.01 cwts. 
From this it appears that the total quantity of fuel consumed per ton of iron made has been less since the gas was used, although the furnaces have been supplied with a greater amount of lean ironstone during the latter period, as will be seen from the increased proportion of ironstone used per ton of iron made, which was as follows:-

Ironstone used per ton of iron made, before taking off gas $61.95 \mathrm{cwts}$.

Ditto ditto after taking off gas 68.44 cwts.

being an increase of 10 per cent. after taking off the gas. Owing also to the greater leanness of the ore, a greater proportion of lime had to be used in the furnaces, the amounts of calcined limestone per ton of iron made being as follows :-

$\begin{aligned} & \text { Calcined Limestone } \\ & \text { per ton of iron made }\end{aligned}$
Ditto ditto before taking off gas . . . $15.08 \mathrm{cwts}$ after taking off gas . . . . $16.86 \mathrm{cwts}$.

being an increase of 12 per cent. in the latter period.

As regards the quality of the iron produced there was no perceptible difference before and after taking off the gas : and from the foregoing particulars it is evident that, if the ironstone had been of equal quality after taking off the gas, the iron produced would have been of a greyer quality; since rather less coal in the furnace has sufficed to reduce 10 per cent. more ironstone and 12 per cent. more lime. This is confirmed by the experience of the working at the Old Park Iron Works, the Willenhall Furnaces, and the Barrow Furnaces near Ulverstone, where the same burden of coal has produced iron of a slightly greyer quality since the gas has been taken off.

The working of these furnaces appears to lead to the conclusion that the open-topped plan of taking off the gas is preferable to the use of a close top ; for with the latter there is occ asionally a considerable pressure on the materials at the top of the furnace, owing to its producing at times more gas than is drawn off. This has a tendency to change the quality of the iron produced from grey to white, as was proved at the furnace at Bilston previously referred to ; and accounts for close-topped furnaces in general working with greater irregularity than open-topped ones. No doubt this disadrantage in close-topped furnaces might be in a great measure obviated by the use of a 
sufficiently powerful chimney to draw off the maximum amount of gas produced by the furnace: but even then the close-topped plan has the disadvantage that the level of the materials in the furnace cannot be seen, which often causes it to be irregularly filled; whereas in the open-topped furnace the fillers have their eye continually on the level of the materials, and have no excuse for the furnace not being always kept full. With a chimney of sufficient height it has been seen that the whole of the gas is drawn off from the open-topped furnaces, except at the times when an excess of gas is made in the furnace, which should be allowed to escape under all circumstances, to prevent the working of the furnace being interfered with ; but with close-topped furnaces it has to be observed that the loss of gas, which inevitably occurs at each time of opening the top for filling, takes place at all times, whether there is a surplus supply of gas or not.

This open-topped plan can be readily adapted to any existing furnaces without the necessity of raising their height, as is requisite with the close-topped plan to allow room for the apparatus. It is also worthy of note that the working of every furnace where this plan has been tried has been improved, which the writer believes is not the case where a close top is used. In several furnaces working with close tops a larger quantity of fuel has been found necessary to produce the same quality of pig iron. In one case at Middlesborough, where a superior description of close top is used, the furnace takes 5 to 7 per cent. more fuel per ton of iron made. At another ironworks there the writer was informed that the extra quantity of fuel required by the furnaces when working with close tops quite counterbalanced the saving of slack at the boilers. This is directly contrary to the experience of those who have used the open-topped plan described in the present paper. There is one point of difference between the two plans which must not be left unnoticed: with a close top the gas may be burnt under boilers, in stoves or heating furnaces, without any high chimneys being necessary to create a draught, the gas being forced down from the furnace by not being permitted to escape at the tunnel head; whereas with an open top a chimney of sufficient height and area to produce a good draught is essential to draw off the whole of the gas produced by a furnace. The writer believes however that a close- 
topped furnace would work much better if the whole of the gas were drawn off as it rises, and that there is a loss instead of any saving in not providing sufficiently powerful chimneys to effect this; the experiment made at Bilston having clearly proved that any pressure of gas in the furnace top is injurious, at least with Staffordshire materials.

In conclusion the writer would remark that the object of this paper is to elicit the facts as to the respective advantages of the several plans that have been tried for using the waste gas from blast furnaces, so as to aid if possible in overcoming the difficulties that have been met with hitherto in its utilisation, and to lead to the general adoption of this important source of economy, which is more especially desirable in the South Staffordshire district since the principal seams of coal are becoming so rapidly exhausted. Only six months ago no use was made of the waste gas from any one of the 126 furnaces then in blast in this district; and at the present time it is only made use of from three, namely one at Wednesbury, one at Willenhall, and one of Mr. Blackwell's at Dudley. In Scotland the plans tried some years ago failed to produce any economical result, so that they were abandoned; and no use is there made of the waste gas up to the present time. In the other iron-making districts of England it is economised at some works but not at others, though the advisability of doing so is now almost universally admitted; and the writer feels sure that in a few years there will not be many ironworks where it is not made use of. The great importance of the question is apparent on considering that the saving effected by making use of the waste gas from one furnace on the plan now described is equal to from

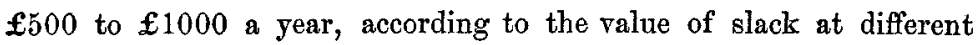
works. Taking the average saving at $£ 750$, if the plan were adopted at only 100 of the 126 furnaces now in blast in South Staffordshire, an

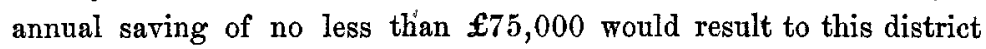
alone. 
The Charmman observed that the plan described in the paper just read appeared a very simple arrangement for taking off the waste gas without the necessity for a close top to the blast furnace. They had had a description of a close-topped furnace at the previous meeting, and he thought it would be desirable to know the further results of its working since that time for comparison with the present open-topped plan.

Mr. C. Cochrane said the statements given at the previous meeting respecting the working of the close-topped furnace at Middlesborough then described had been fully confirmed by subsequent results. The close-topped furnace from which the gas was taken off was one of three furnaces, all working under the same conditions of materials and blast; and the results of working for the month of September were that the average quality or "number" of iron made by the closetopped furnace during the month was $3 \cdot 16$, taking the range of numbers 1 to 4 for foundry iron and 4 to 6 for forge iron, and the two other furnaces yielded average qualities of 3.18 and $3 \cdot 01$, showing no appreciable difference in quality in the make of the close-topped furnace. The consumption of coke was $31.89 \mathrm{cwts}$. per ton of iron in the close-topped furnace, and $31.21 \mathrm{cwts}$. and $31.02 \mathrm{cwts}$. in the two other furnaces, showing a consumption of 2 per cent. and 3 per cent. more coke respectively in the close-topped furnace, which was a further improvement as had been then anticipated upon the result stated at the previous meeting, when the consumption of coke had been reduced from 7 per cent. to 5 per cent. greater in the close-topped furnace. The total make of iron in the close-topped furnace during the month was $818 \frac{1}{2}$ tons, of which 31 tons were mottled iron and $16 \frac{1}{2}$ tons white iron, amounting altogether to less than 6 per cent. of mottled and white iron out of the whole quantity. In some closetopped furnaces the working of the furnace was impaired by the mode of filling, the top being closed by a cone that was lowered into the furnace in charging, which reduced the height of the materials, so that the heat was not so thoroughly taken up and a greater consumption of coke was required; but by having the cone made to draw upwards for charging, on the plan he had adopted, the materials could be kept up to the same height as before, and any objection on this ground removed. 
One canse of the increased make of the furnace described in the paper had he thought been overlooked, namely the improvement arising from enlarging the tunnel head; for it was well known that a wider mouth increased the make of a furnace, by allowing a larger quantity of blast to pass through it than was possible with the smaller top.

Mr. G. Thomson asked whether the 31 cwts. of fuel consumed in the close-topped furnace per ton of iron made was coke or coal.

Mr. C. Cochrane replied that the fuel was all coke, as they could not use their coal in the blast furnace, since it would cake and arch over and check the working of the furnace.

Mr. J. Fenton thought the make of the open-topped furnace described in the paper, 104 tons per week, seemed a small amount for a hot-blast furnace; and he enquired what was the temperature of the blast, and whether the ore was calcined before going into the furnace. At Low Moor the weekly make of one large furnace was about 120 tons of cold-blast iron, from a lean stone containing only 28 per cent. of iron; the furnaces were rather larger than that described in the paper, measuring about 12 feet diameter at the top and 14 feet at the boshes. He asked whether the limestone used was carboniferous or magnesian.

Mr. LLOXD said the temperature of blast was about the melting point of lead, but sometimes below. The ironstone used at Brymbo was of a lean description, containing only about 26 per cent. of iron, so that the make of the furnace was rather less than would be got with such an ore as had been mentioned. In the furnace at Wednesbury, the make of which was about 124 tons per week, the ironstone used was chiefly that known as Blue Flat, containing rather more than 30 per cent. of iron; and also New Mine ironstone, containing about 25 per cent. of iron : the quality of iron produced was very good. The ore was calcined beforehand, and the limestone was the silurian. The furnace was 10 feet diameter at the top, 12 feet at the boshes, and 4 feet 6 inches in the hearth, and the total height was 47 feet to the level of the filling plates.

Mr. W. Mathews observed that if the coal was not precisely the same in quality in both cases, the make of iron would of course be different : he had had an opportunity recently of seeing the working of the furnaces at Low Moor, and was satisfied the difference in quality 
of coal fully accounted for the difference in make; and if the coals used at the two works were interchanged, the make of the furnaces would be reversed. The coal used at the Old Park Iron Works was not a good coal for the blast furnace as compared with that used at Low Moor, and the make of iron obtained he considered was good work for such a quality of coal; but the superior coal at Low Moor made both a good quality of iron and a good yield.

Mr. J. Fenton asked whether the coal was all coked or used raw.

Mr. LLoYd said that half of each burden consisted of Heathen coal and Thick coal mixed, and was used raw; but the other half consisting of New Mine coal was coked before being used, to get rid of the sulphur which it contained in its raw state.

Mr. E. A. CowPER thought there was no doubt the increased make of iron obtained after taking off the gas was due to the increased quantity of blast delivered into the furnace, owing to the increased supply of steam to the blast engine when the boilers were heated by the gas, all risk of neglect or irregularity in the firing being removed; this seemed the most satisfactory explanation, because the make was increased in both furnaces, not that only from which the gas was taken off. The utilisation of the waste gas was of the utmost importance to the welfare of the South Staffordshire district, as it would result in the manufacture of iron being cheapened; he was glad that attention was now being called generally to the subject.

Mr. N. N. Solty had had the gas taken off for three months from one furnace at Willenhall in the manner described in the paper, and the one furnace supplied gas enough for all the four boilers of the blast engine, without the use of any slack at all, except during the first week of starting, when a little slack had been burnt for ensuring keeping up the steam while the furnace from which the gas was taken off was standing. There were three furnaces of 11 feet diameter at the top and 14 feet 6 inches at the boshes, each making about 170 tons of iron per week, and the iron made by the furnace from which the gas was taken off was rather greyer than in the two other furnaces with the same burden of coal, which showed an advantage in taking off the gas; there had never been any white or mottled iron from that furnace since the gas was taken off, and the furnace had never slipped in the least, 
but worked with great regularity. The quantity of iron made per week was not altered since the gas was taken off, but the yield of the ironstone was decidedly better than in the other two furnaces; and the yield of coal was also better, though this might be partly accounted for by the furnace having had a new hearth recently: the coal used was entirely New Mine coal, which was a pure coal, but not strong for standing the blast.

Mr. W. Mathews asked whether the distance of the boilers from the blast furnace made any difference in the efficiency of the gas; he supposed there would be no difference, because the gas was not ignited till it reached the boilers, and was therefore conveyed to them simply like common coal gas. He had long felt the importance of utilising the waste gas, but had hesitated to apply it at his own furnaces, principally for the reason that it would have to travel a long way to reach the boilers, past the blast engine and over a road: he had therefore delayed taking off the gas, as many other ironmasters doubtless had done, till he had seen the results of the trials at other places. No previous mode of taking off the waste gas had appeared quite free from objection, but the plan now described seemed to answer completely, and Mr. Blackwell had also tried the same plan recently with most beneficial effects. He fully expected now that the bulk of the furnaces in South Staffordshire would have the gas apparatus applied before long. The relative cost of slack in different districts was of course a question that would affect the value of the plan materially, and in the North of England where its cost was rather excessive it was more necessary to save fuel by taking off the gas; but at his own works only 4 or 5 cwts. of slack were burnt under the boilers per ton of iron made, and as the slack was delivered very cheap from the pits close by there was but little margin for economy. At many works in the district however fuel was much dearer; and in the present state of the iron trade the smallest saving was of importance, particularly when the ultimate exhaustion of the present local supply of coal was taken into consideration.

An important application of the small coal of the district was now being carried out by Mr. Charles Cochrane, who had recently put up some ovens at Dudley for converting it into a serviceable coke by 
mixing with it some bituminous slack from South Wales; by this means he had succeeded in making a good useful coke out of what was otherwise of no use but to burn under engine boilers. The cost of Welsh small coal limited the adoption of such a plan at present, but this would soon be materially reduced by increased facilities for carriage by railways, which would alnost make South Wales and South Staffordshire parts of the same district, as North and South Staffordshire were now become one district by the extension of railway communication.

Mr. LLOYD said there was no difficulty or objection to conveying the gas a considerable distance from the furnace, and there was not the slightest difference in its efficiency, whatever distance it was conveyed to ; just as the gas supplied to Birmingham from Westbromwich was exactly the same in Birmingham as at the works 6 miles off.

Mr. E. A. Cowper stated that the gas was conveyed 400 or 500 feet at Messrs. Bolckow and Vaughan's furnaces at Eston near Middlesborough, without any difficulty; it was only necessary to have sufficient draught or pressure to overcome the friction of the gas along the pipe. These furnaces had the top closed for taking off the gas with a cone or bell that was lowered for charging, and were making grey foundry pig. He asked whether the waste gas had been applied to the hot-blast stoves in any of the cases described in the paper, as well as to the boilers.

Mr. N. N. Solux said the gas was not yet employed for heating the hot-blast stoves at the Willenhall Furnaces, but they were getting ready for applying. it for that purpose; the gas would be taken in at the top of the stoves, and out at the bottom, and thence along a culvert to the chimney, which was 120 feet high and 8 feet diameter inside all the way up.

Mr. LLOYD observed that in this plan of taking off the waste gas by a tube inserted in the materials of the furnace there was found to be a great accumulation of dust in the bend at the top of the furnace, the bend being sometimes half full of dust after a week's work, and a valve had to be placed there for raking ont the dust every Sunday. This dust consisted of little shelly pieces of ironstone mixed with coke dust, which was of no use in the furnace, and must cause an obstruction to 
the blast by going down with the materials; and he thought the circumstance of its being drawn off with the gas in this plan accounted partly for the increased make of the furnace since the gas was taken off, by relieving the furnace and allowing the blast to pass through more freely. They had tried carefully puddling two or three heats from this furnace and from the two other ordinary furnaces, and the result seemed a little in favour of the furnace from which the gas was taken off, 2 lbs. more weight of wrought iron being obtained in one case and $3 \mathrm{lbs}$. in another out of a charge of $4 \mathrm{cwts}$. of pig iron.

Mr. F. J. Bramweld remarked that in former trials of close-topped furnaces the inferior quality of iron obtained was considered to arise not from the pressure of gas produced by the closed top, but because the waste gas burning out of the tunnel head in ordinary open-topped furnaces produced a beneficial effect in preparing the charge for going down into the furnace, which was lost when the top of the furnace was closed; but if only the surplus gas was drawn off by the centre tube in the plan now described, leaving enough still burning out of the open furnace top, this effect wonld not be interfered with. $\mathrm{He}$ enquired whether the gas was ever so completely drawn off that no flame at all was visible at the tunnel head, and if so whether any difference had been observed in the iron produced during that time.

Mr. LLoyd replied that sometimes all the flame went down for a short time, with scarcely more than that of a candle to be seen playing at intervals through the crevices of the materials, so that a man could even walk across the top of the furnace; but this absence of flame never continued more than a quarter or half an hour, so that there was no means of judging whether the make of iron was affected by it. He thought the materials in the furnace must give out very variable quantities of gas, as there was so much variation in the flame burning out at the top.

Mr. N. N. Solly said he had never seen his furnace entirely free from flame, but there was much less flame at some times than at others, and frequently scarcely any.

Mr. C. Cochraxe thought nearly all the gas must be taken off by the centre tube, if the flame at the tunnel head was so small as frequently to be scarcely visible; and the small quantity of gas burning 
out at the open top could produce but little beneficial effect on the materials. In such cases the open-topped plan of taking off the gas seemed to be practically under the same condition as a close top with the whole of the gas taken off.

Mr. LLord abserved that the open top was a safeguard against any risk of the furnace being thrown to white iron when there was much gas given off from the materials. On one occasion he had observed a large quantity of flame at the tunnel head, and if the top of the furnace had been closed white iron would he thought certainly have been made then. If a comparison were made in the South Staffordshire district between the two modes of taking off the gas, with a close-topped and an open-topped furnace working side by side, he had no doubt the open-topped furnace would prove decidedly the better; for in the previous trials they had made of close-topped plans, the iron was soon found to be injured in quality and the make fell off from 100 tons per week to 60 tons.

The Chairmax enquired whether any accidents from explosion had oceurred at any of the furnaces from which the gas was taken off.

Mr. N. N. Solwy had had no accident that had caused any damage, and no explosion of gas in the gas main had ever occurred at his furnaces, but the gas main was fitted with a considerable number of safety valves. There had been two slight explosions in the fore portion of the blast pipes, but they were not sufficient to do any injury to the apparatus or machinery; they arose from want of safety valves. on that part of the pipes, but two had now been added there, and since then no accident had occurred. Explosions generally ocourred at: casting time, when the gas was prevented from escaping through the gas main by a damper which was then shut to stop the draught; and the gas being kept back and confined in the furnace must have fonnd. its way through the tuyeres into the blast pipes, and there mixing: with air exploded in the fore portion of the pipes in front of the furnaces. No such explosion ever occurred before the gas apparatus was put up, because then the gas could always escape sufficiently at the trnnel head at casting time; and they had previously taken the precantion to place valves on the blast pipes at the back of the furnaces. 
One effect of this mode of taking off the waste gas was he thought that the draught of the chimney removed much of the sulphur and other impurities from the furnace, enabling a stperior quality of iron to be made. Besides the saving of fuel produced by using the gas, there was as much advantage to be gained from the saving of labour in boiler repairs ; for since the gas had been used he had not had the slightest repairs to the boilers, whereas previously repairs were required almost every week : the attendance of stokers for the boilers was also saved, and labour and horse power for removing ashes, \&c.

Mr. O. Cochrane said there was little danger of explosion in taking off the gas, if there was a proper arrangement of tubes and sufficient provision of safety valves. He had now had the closetopped furnace at Middlesborough at work for eleven months since first starting, without a single explosion to do any mischief.

Mr. C. W. Siemens thought there was less risk of explosion in taking off the gas from a close-topped furnace, because there was no chance of any admixture of air taking place; but in an open-topped furnace the draught of the chimney might draw in air through the end of the tube when the furnace stopped, and make an explosive mixture.

Mr. C. Markham said at the close-topped furnaces at Marquise in France, that he had mentioned at the previous meeting, there were no safety valves, and there had never been an instance of the gas exploding; but he doubted whether safety valves would be of much use in case of explosion, as the explosion would be instantaneous, and he thought the mischief would be done before the safety valves had time to act.

Mr. C. Cochrane considered the safety valves were essential as a precaution against damage by explosion; for they had frequently had explosions at Middlesborough in which the safety valves were the only safeguard, and the entire apparatus would have been blown to pieces had there been no valves; but the valves flew open at the instant of explosion, and completely prevented all injury.

Mr. LLOYD said their gas main had been saved by the safety valves several times from being blown up by explosions when they tried using the gas about ten years ago; the valves shot open suddenly, 
and the men standing near had been blown down, but no damage was done. No explosions had occurred since they commenced taking off the gas on the present open-topped plan.

The Chatrman asked whether there was a damper for cutting off the draught of the chimney at casting time.

Mr. LloYd said there was a slide valve in the gas main at each boiler, which was shut when the furnace was standing, but the furnace continued making a little gas at that time, which came down into the main mixed with air and sometimes exploded when lighted again. He proposed providing a stop valve at the top of the descending gas main close to the bend, to be closed when the furnace was standing; the seating might be made with a deep groove all round, which would become filled with the dust drawn over from the furnace, and the rim of the valve bedding in the dust would form a gas-tight joint; this would be an improvement by entirely preventing either gas or air from passing into the main while the furnace was standing.

Mr. E. A. Cowpen remarked that where there were several furnaces connected to the same gas main there might be danger of drawing in air through one furnace that was standing, while gas was being drawn off from the others, forming an explosive mixture the gas main. At some furnaces in the North of England the gas was taken off from all the furnaces by one large main, 6 feet diameter, with a row of safety valves all along the top; when an explosion occurred there, it ran along the main, all the valves lifting successively, and no injury was done.

Mr. LLoy observed there was one difficulty they had experienced in taking off the gas, which had not arisen in other cases: a considerable quantity of pitch was deposited in the gas main, which caused great annoyance, blocking up the bends and choking the slide valves leading to the boilers; they were obliged to get a red-hot iron to melt the pitch in order to open the valves, and men had to be sent down the descending gas main to clear it out. This trouble had not occurred in South Wales or at Brymbo; and at Willewhall, where it was experienced slightly at first, it was now no longer met with. 
The Chairmar observed that the subject of the paper was one of great importance, and he hoped it would be carried on at a future meeting with the results of continued experience in this mode of taking off the waste gas. He proposed a vote of thanks to $\mathrm{Mr}$. Lloyd for his paper, which was passed.

The following paper was then read:- 


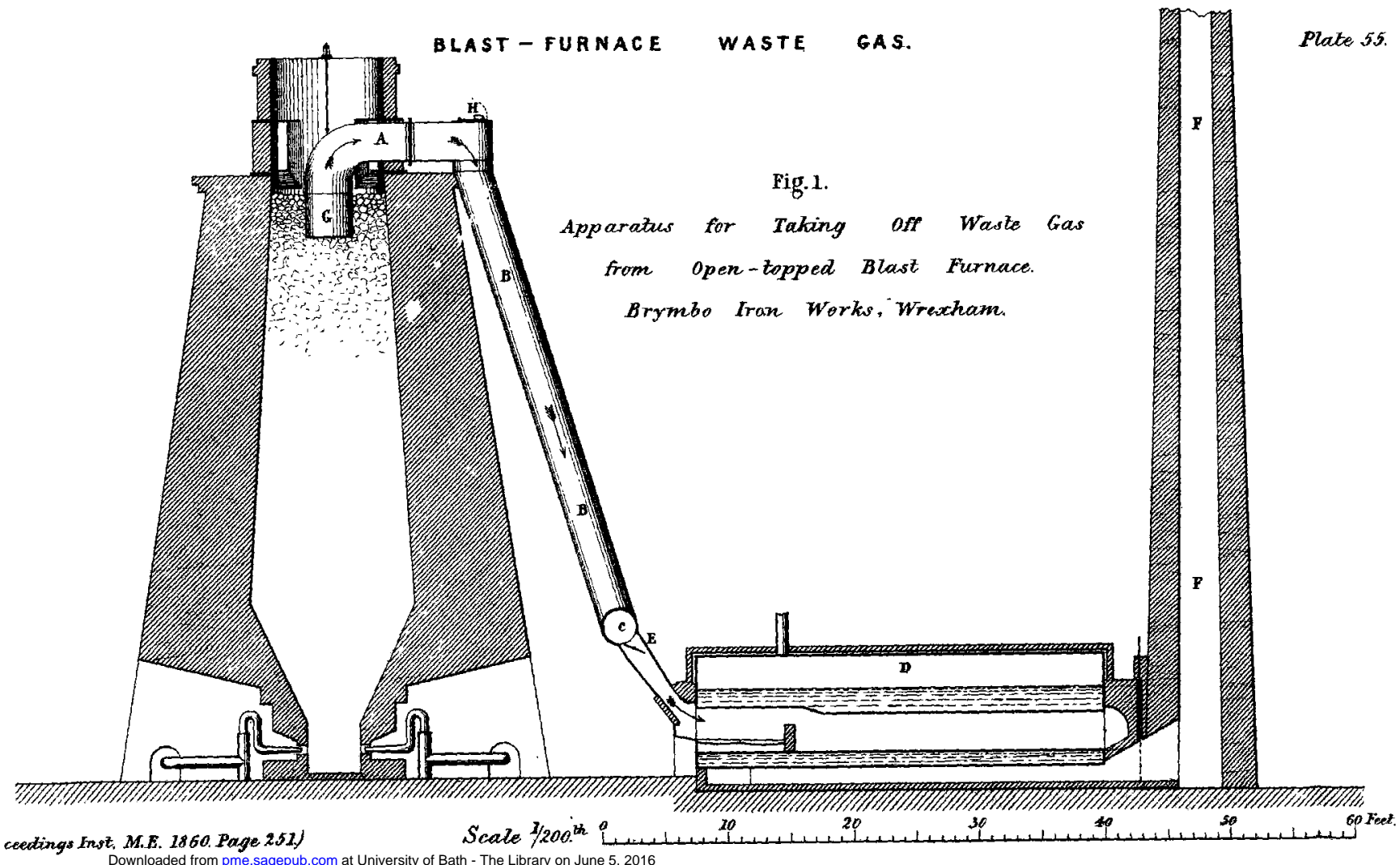

Downloaded from pme sagepub com at University of Bath - The Library on June 5, 2016 


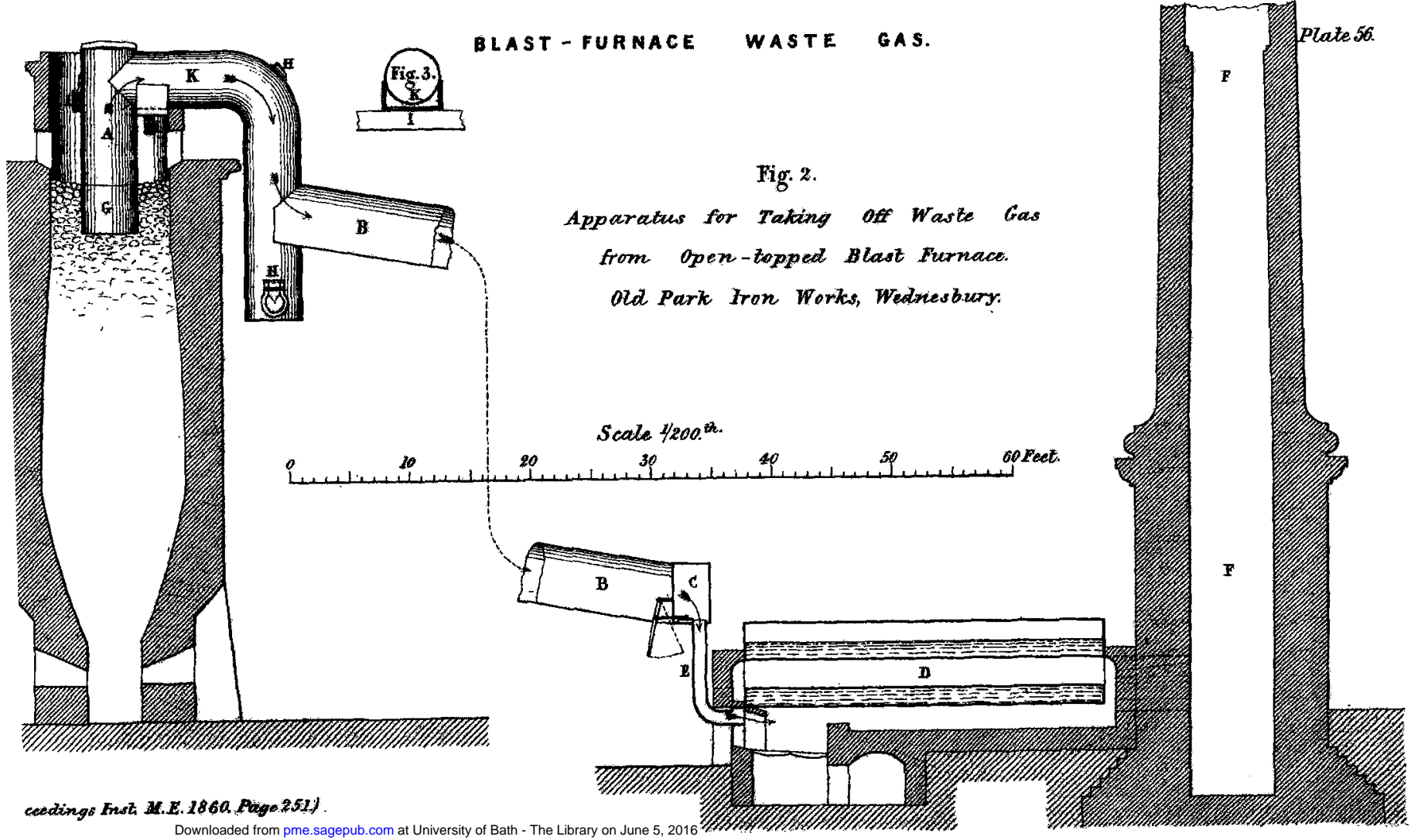




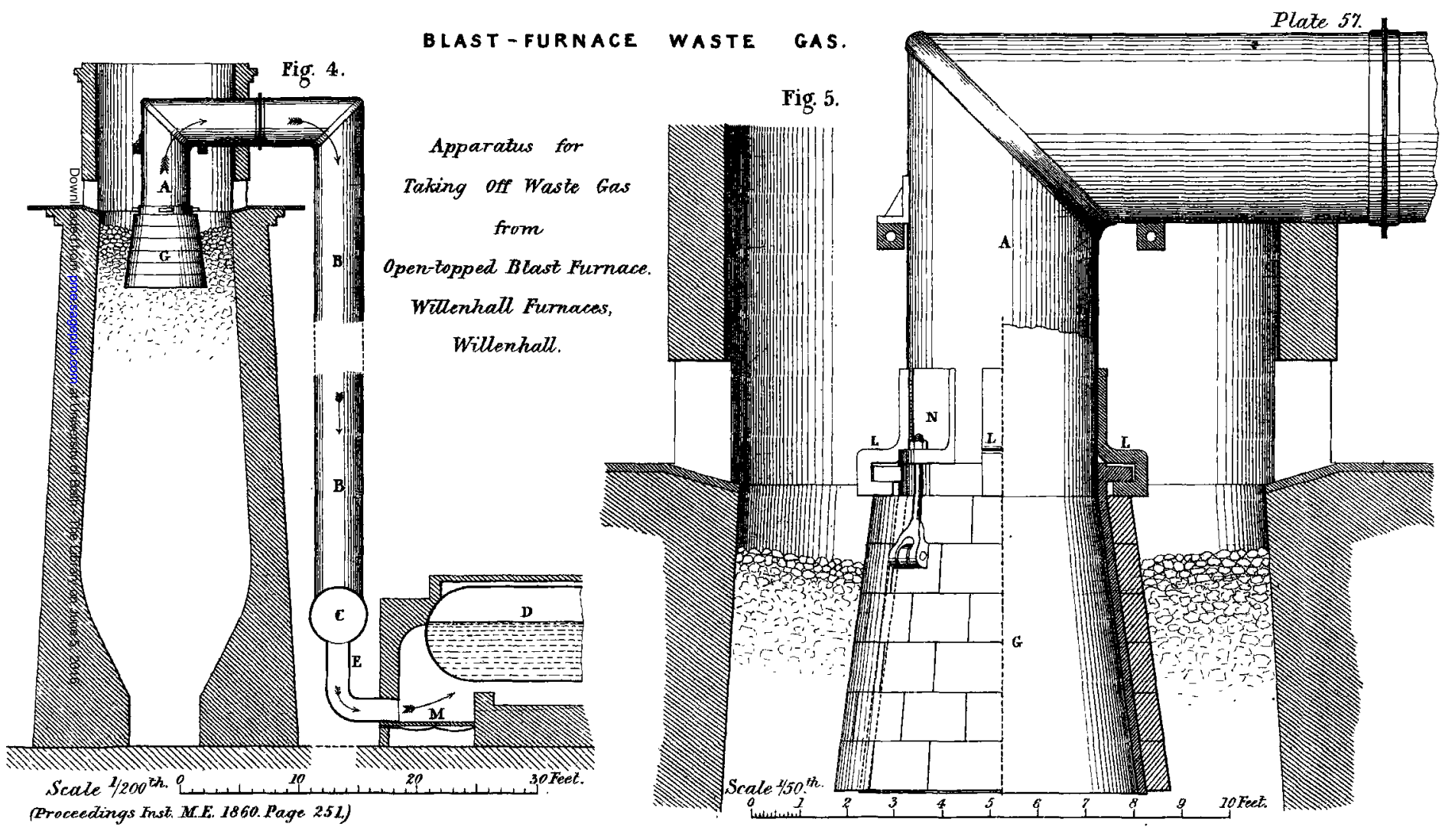


QLAST - FURNACE WASTE GAS.

Plate 58.

Fig. 6. Open Top of Furnace at Brymbo Iron Works, Wrexham.

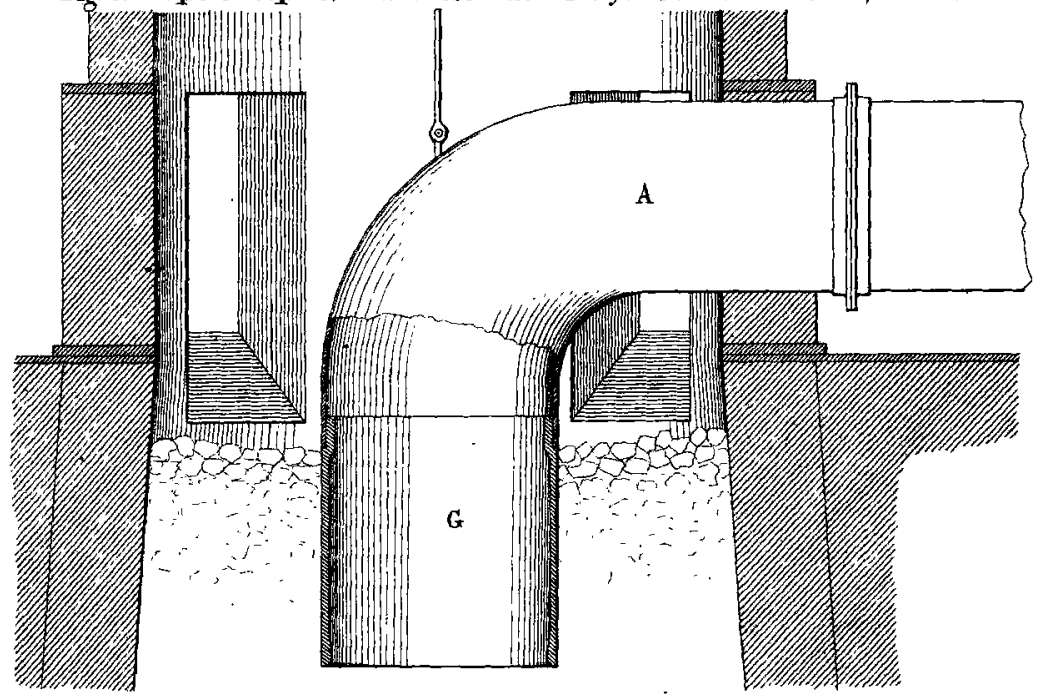

Fig. 7. Open Top of Furnace at old Park Iron Works, Wednestury.

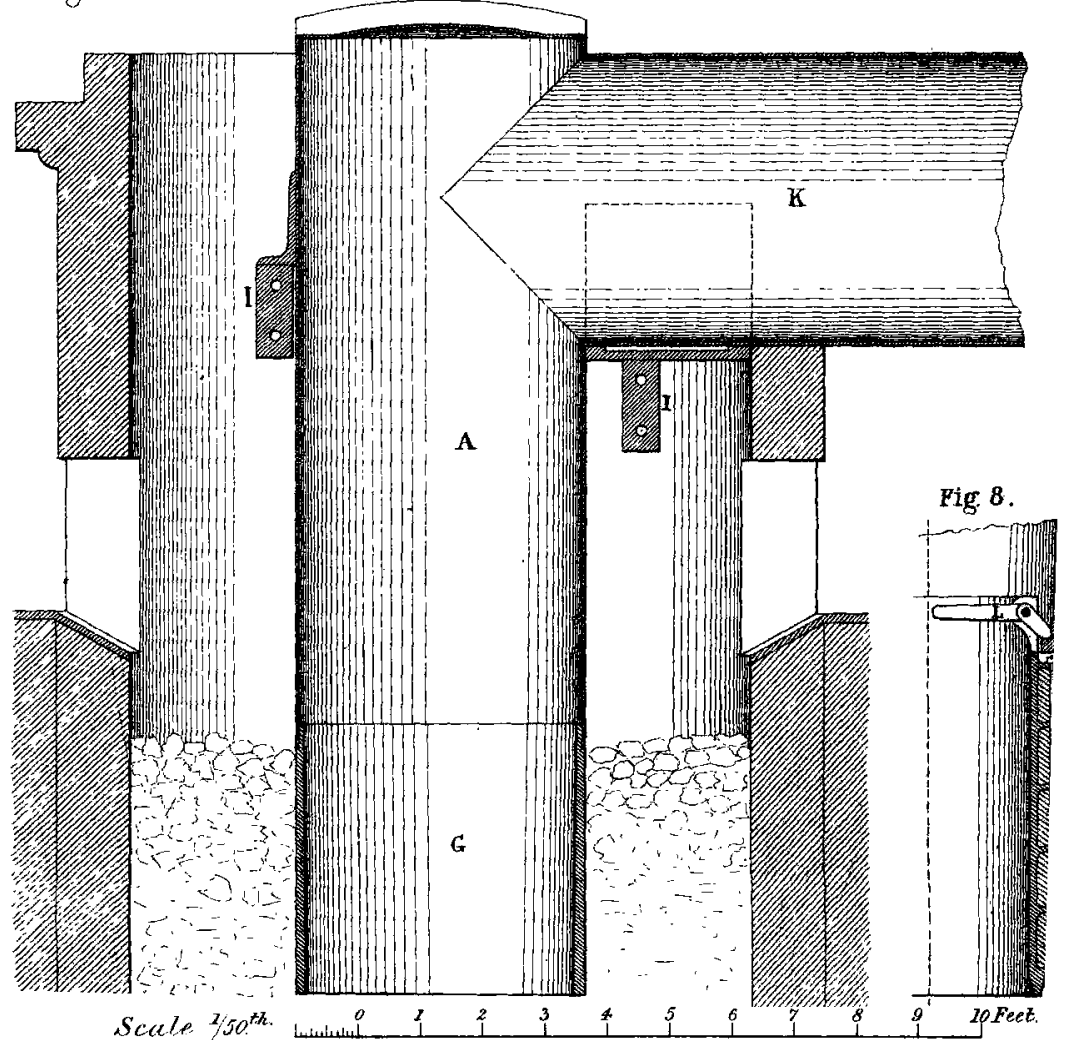

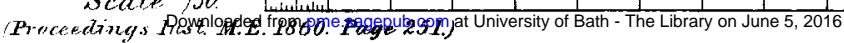

